\title{
Encephalopathy following ingestion of Lead-contaminated opium; magnetic resonance imaging findings
}

\author{
Maryam Haghighi-Morad ${ }^{1}$, Nasim Zamani ${ }^{2,3}$, Hossein Hassanian-Moghaddam ${ }^{2,3^{*}}$ (1) and Maziar Shojaei ${ }^{4}$
}

\begin{abstract}
Background: Encephalopathy is an uncommon but serious presentation of lead toxicity.

Objective: We aimed to determine and follow-up the brain magnetic resonance imaging (MRI) abnormalities in the patients with lead encephalopathy due to ingestion of lead contaminated opium.

Methods: In a cross-sectional study during lead-contaminated opium outbreak, all lead-poisoned patients with any signs/symptoms of encephalopathy were included.

Results: Of 19 patients with lead encephalopathy, five died early and other five could not be sent to MRI during their hospitalization period. Mean age was $51 \pm 11$ years and males were dominant (89\%). Median [IQR] blood lead level (BLL) was 101 [81, 108] $\mu \mathrm{g} / \mathrm{dL}$ (range; 50 to $200 \mu \mathrm{g} / \mathrm{dL}$ ). There was no correlation between MRI findings and signs/symptoms. MRI was normal in six and abnormal in three. Bilateral symmetric involvement of parieto-occipital lobes was observed. Gray matter, gray-white matter junction, and subcortical white matter were also affected. Follow-up MRI was performed in two with abnormal MRI which showed complete and near complete resolution of the abnormalities after cessation of opium use and treatment. Conclusion: There was no correlation between MRI findings and BLL. Complete recovery of brain MRI lesions was detected after cessation of opium use.
\end{abstract}

Keywords: Lead, Toxicity, Outbreak, Encephalopathy, Magnetic resonance imaging, Opioid

\section{Background}

Encephalopathy is an uncommon but serious presentation of lead toxicity [1]. Lead encephalopathy is generally described by sudden commence of the manifestations including severe headache, vomiting, convulsions, mental aberration and excitement [2]. Although blood lead levels (BLLs) of higher than $100 \mu \mathrm{g} / \mathrm{dL}$ generally accompany with lead encephalopathy, much lower levels (as low as $38 \mu \mathrm{g} / \mathrm{dL}$ ) may also result in encephalopathy in chronic toxicities [1]. During an outbreak in Iran, opium users were evaluated at Loghman-

\footnotetext{
* Correspondence: hassanian@sbmu.ac.ir; hasanian2000@yahoo.com

${ }^{2}$ Social Determinants of Health Research Center, Shahid Beheshti University of Medical Sciences, Tehran, Iran

${ }^{3}$ Department of Clinical Toxicology, Loghman-Hakim Hospital, School of Medicine, Shahid Beheshti University of Medical Sciences, Tehran, Iran Full list of author information is available at the end of the article
}

Hakim Hospital, and found to have high BLLs. Leadcontaminated opium was considered as the source of oral contamination [3-5]. Lead-contaminated opium has been recently discussed in the literature [6]. The objective of the current report was to determine the magnetic resonance imaging (MRI) characteristics of lead encephalopathy due to ingestion of lead-contaminated opium. We also aimed to perform a follow-up MRI after treatment in these patients to see if treatment improved their MRI abnormalities.

\section{Methods}

\section{Study design and setting}

This cross-sectional study was carried out during an outbreak of lead toxicity due to lead-contaminated opium 
in Tehran between September 2016 and August 2017 [3]. All data was pooled from a referral center for poisoned patients with annual admissions of almost 24,000 intoxicated patients supposed to be the biggest inpatient clinical toxicology center of the world [7].

\section{Selection of participants}

All lead-poisoned patients who referred with any signs/ symptoms of encephalopathy including loss of consciousness or seizure were considered as the potential participants through a chart review of the admitted patients during outbreak [3]. Diagnosis of lead toxicity was made based on BLLs higher than normal (normal range; $<10 \mu \mathrm{g} / \mathrm{dL}$ ) checked by atomic absorption technique (Graphite Furnace Atomic Absorption Spectrometry [GFAAS]). After termination of treatment, BLL was followed using Lead Care II device.

Our MRI unit has recently been established with no supporting ventilator for comatose patients. Therefore, only patients who were stable and not intubated could be sent for MRI. If a comatose intubated patient improved and could be extubated, he/she would also be considered to be transferred to MRI unit where MRI was performed at the earliest convenient time. Bedside electroencephalogram (EEG) was done based on the treating physician's decision.

Our primary outcome was MRI findings of the patients with lead encephalopathy while determination of the demographic characteristics of the patients and follow-up results of the abnormal MRIs were the secondary outcomes. MRI was performed using Vantage Elan 1.5 T MR system (Toshiba Medical Systems Corporation [TMSC]).

\section{Statistical analysis}

For the description of quantitative variables with normal and non-normal distribution, mean $( \pm \mathrm{SD})$ and median [IQR interquartile range] were used, respectively. For qualitative variables, percent of frequency was used. To compare normal/abnormal MRI findings with categorical variables, Fisher's exact test was applied. For comparing continuous variables with normal/abnormal MRI findings, t-test or Mann-Whitney $U$ test was used. A $P$ value less than 0.05 was considered to be statistically significant. Statistical package for social sciences (SPSS) version 17.0 (SPSS Inc., Chicago, Ill, USA) was used for analysis.

Our institutional ethics committee approved this study.

\section{Results}

Almost 3800 lead-poisoned opium user patients were admitted to our center [3]. Of the 19 patients who were eligible to be entered, five died early and MRI was out of service for another five patients because of technical reasons. Finally nine patients were evaluated by MRI. Lab tests for other medications/toxins that could affect brain MRI (including carbon monoxide, methanol, pesticides, cyanide, and sympathomimetics) were negative. Hypoxic encephalopathy was also excluded using cases without a period of hypoxia greater than $3 \mathrm{~min}$ or an out of hospital respiratory arrest as a clinical finding. Table 1 shows epidemiological characteristics of the patients.

Their mean age was $51 \pm 11$ years (range; 39 to 72 ) and males were dominant (89\%). Median [IQR] blood lead level was $101[81,108] \mu \mathrm{g} / \mathrm{dL}$ (range; 50 to 200) with a mean hemoglobin level of $9.2 \pm 1.7 \mathrm{mg} / \mathrm{dL}$ (range; 7.6 to 12.8).

EEG was performed in three and was normal in one and abnormal in two of those who had MRIs (Table 1).

MRI was normal in six cases (67\%) and showed pathologic changes in three cases (Figs. 1, 2, 3). There was no statistically significant difference between those with and without MRI abnormalities in terms of BLL, hemoglobin level, age and clinical manifestations.

Figures 1, 2, 3 show MRI findings of three patients during hospitalization. On follow-up, all patients became symptom-free after quitting the lead-contaminated opium or initiation of lead chelating agents. Two, out of three patients with abnormal MRI accepted to undergo the follow-up MRI. The time interval between the two MRIs was three and twelve months in cases 3 and 1, respectively. MRI findings resolved with no major neurological damage. BLLs were 8 and $25 \mu \mathrm{g} / \mathrm{dL}$ on follow-up evaluations of these two patients, respectively. We could not find any correlation between MRI findings and BLLs, age, $\mathrm{Hb}$, EEG, and signs/symptoms.

\section{Discussion}

Opioid abuse causes acute and chronic effects on neurovascular system. The most common encountered acute neurovascular effect of opioids on central nervous system is ischemia which is more often observed with intravenous injection of the drugs in comparison to oral ingestion or inhalation. The suggested mechanisms for acute ischemia due to opioids are reversible vasospasm, vasculitis and embolic events.

Reversible vasospasm is the result of stimulation of muopioid receptors of the vascular smooth muscles. Immune mediated response to opioids or impurities causes vasculitis. Also embolization of small insoluble particles is a potential mechanism of ischemic events due to opioids. Globus pallidus and after that hippocampus and cerebellar water shed areas are the most commonly reported location of ischemic infarctions due to opioids. Chronic neurovascular abnormalities from opioid abuse are represented with diffuse, symmetric bilateral T2W hyper intensities in the subcortical and peri ventricular white mater which are secondary to microvascular ischemic changes $[8,9]$. None of these findings due to opioids toxicity are observed in our patients. 
Table 1 Selected characteristics of patients with lead encephalopathy

\begin{tabular}{|c|c|c|c|c|c|c|c|c|}
\hline No & $\begin{array}{l}\text { Age } \\
\text { range (Year) }\end{array}$ & Gender & $\begin{array}{l}\mathrm{BLL} \\
(\mu \mathrm{g} / \mathrm{dL})\end{array}$ & $\begin{array}{l}\mathrm{Hgb} \\
(\mathrm{mg} / \mathrm{dL})\end{array}$ & Signs \& Symptoms & EEG Interpretation & $\begin{array}{l}\text { Chelating } \\
\text { agents }\end{array}$ & $\begin{array}{l}\text { MRI } \\
\text { finding }\end{array}$ \\
\hline 1 & $50-60$ & M & 50 & 12.8 & $\begin{array}{l}\text { Seizure, abdominal pain, } \\
\text { agitation, constipation }\end{array}$ & $\begin{array}{l}\text { mild diffuse } \\
\text { encephalopathy }\end{array}$ & No & abnorma \\
\hline 2 & $70-80$ & M & 200 & 8.7 & $\begin{array}{l}\text { Delirium, abdominal pain, } \\
\text { weakness, constipation }\end{array}$ & not done & $\mathrm{BAL}+\mathrm{EDTA}$ & abnorma \\
\hline 3 & $30-40$ & M & 68 & 7.6 & $\begin{array}{l}\text { Abdominal pain, constipation, } \\
\text { confusion, seizure }\end{array}$ & $\begin{array}{l}\text { moderate diffuse } \\
\text { encephalopathy }\end{array}$ & $\mathrm{BAL}+\mathrm{EDTA}$ & abnorma \\
\hline 4 & $40-50$ & M & 95 & 8.1 & $\begin{array}{l}\text { Abdominal pain, weakness, } \\
\text { myalgia, confusion, seizure, } \\
\text { insomnia, loss of appetite, dysarthria, } \\
\text { gait disturbance, steering, delirium, } \\
\text { seizure, constipation, ventricular } \\
\text { tachycardia and cardiac arrest } \\
\text { before arrival }\end{array}$ & diffuse alpha activity & $\mathrm{BAL}+\mathrm{EDTA}$ & normal \\
\hline 5 & $40-50$ & M & 101 & 10.2 & $\begin{array}{l}\text { Consciousness fluctuation, delirium, } \\
\text { hallucination, disorientation, upper } \\
\text { motor neuron weakness }\end{array}$ & $\begin{array}{l}\text { moderate diffuse } \\
\text { encephalopathy } \\
\text { (cortical dysfunction) }\end{array}$ & $\mathrm{BAL}+\mathrm{EDTA}$ & normal \\
\hline 6 & $50-60$ & M & 107 & 8.4 & $\begin{array}{l}\text { Repeated seizure, weakness, agitation, } \\
\text { loss of appetite, abdominal pain, } \\
\text { constipation }\end{array}$ & $\begin{array}{l}\text { mild diffuse cortical } \\
\text { dysfunction }\end{array}$ & $\mathrm{BAL}+\mathrm{EDTA}$ & normal \\
\hline 7 & $50-60$ & M & 105 & 7.6 & $\begin{array}{l}\text { Abdominal pain, confusion, disorientation } \\
\text { to time, constipation }\end{array}$ & Normal & $\mathrm{BAL}+\mathrm{EDTA}$ & normal \\
\hline 8 & $40-50$ & M & 110 & 10.6 & Agitation, seizure, delirium & not done & $\mathrm{BAL}+\mathrm{EDTA}$ & normal \\
\hline 9 & $50-60$ & $\mathrm{~F}$ & $>65$ & 9.1 & $\begin{array}{l}\text { Seizure, delirium, severe agitation, } \\
\text { nausea and vomiting, confusion }\end{array}$ & $\begin{array}{l}\text { mild diffuse } \\
\text { encephalopathy }\end{array}$ & $\mathrm{BAL}+\mathrm{EDTA}$ & normal \\
\hline
\end{tabular}
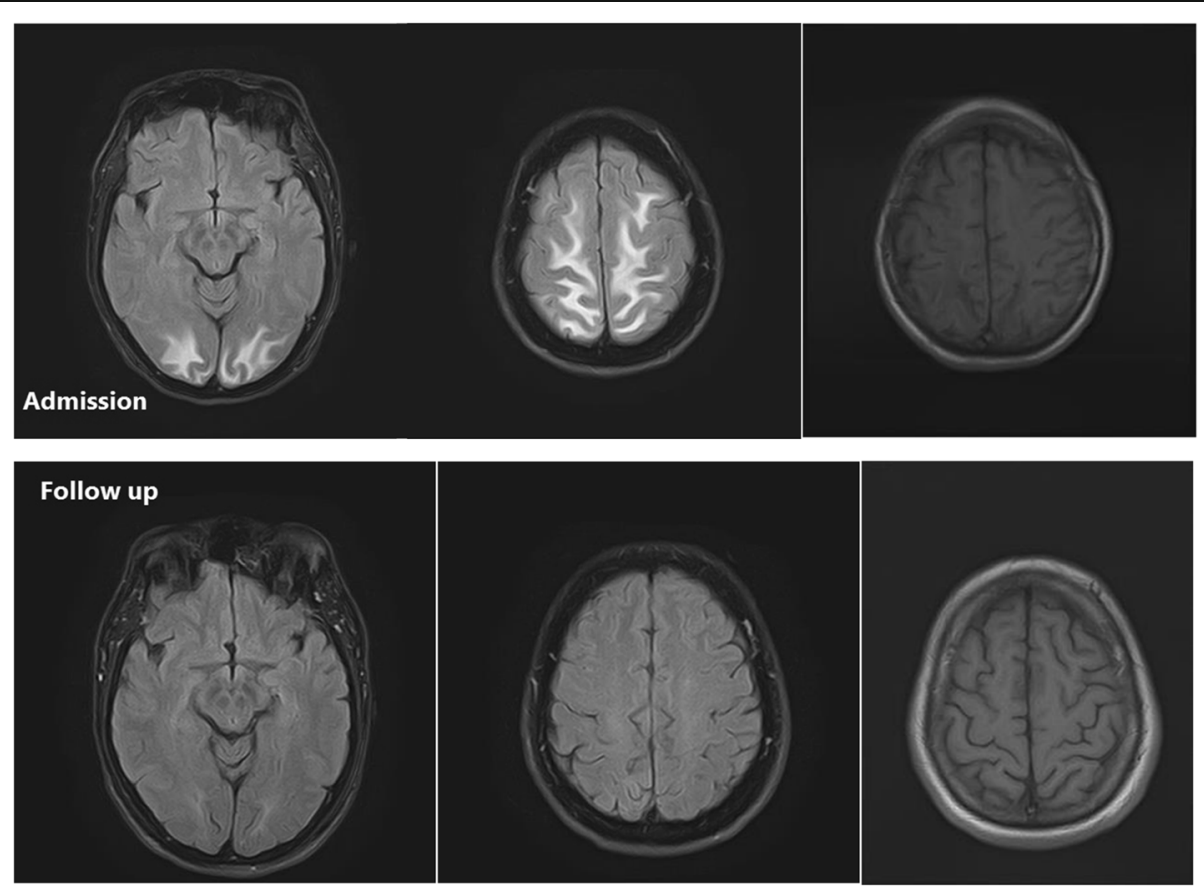

Fig. 1 (Case 1): On admission MRI: MRI shows bilateral symmetric involvement of two areas in parasagittal parietal and occipital lobes. Gray matter, gray white matter junction, and the subcortical white matter are involved. The lesions are bright on T2-weighted and FLAIR images and hypointense on T1-weighted images. No evidence of diffusion restriction is noted. Follow-up MRI: Lesions completely resolved on the repeat MRI without chelation therapy 

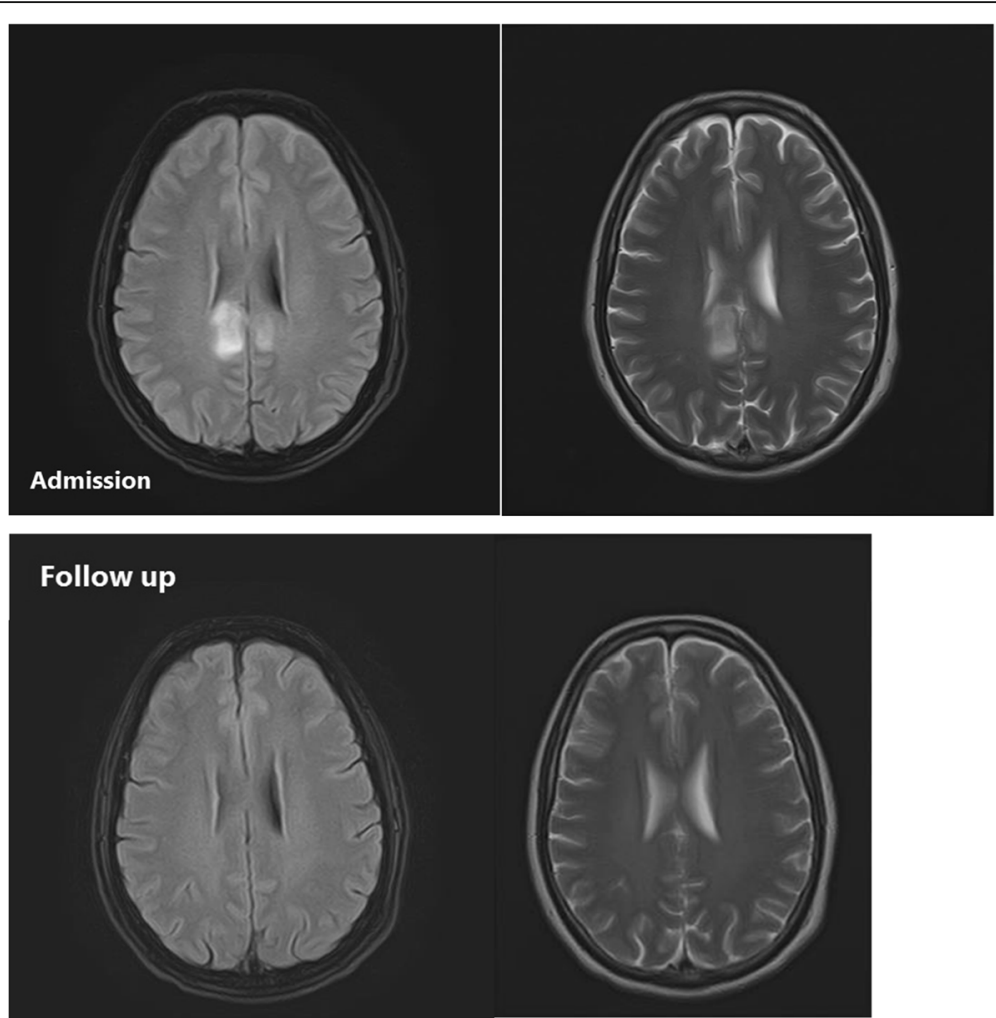

Fig. 2 (Case 3): Admission MRI: MRI shows symmetric involvement of the parietal lobes in the parasagittal region. Gray matter, gray white matter junction, and subcortical white matter are affected. The lesions were bright on T2-weighted and FLAIR images and hypointense on T1-weighted images. Mild to moderate edema is associated with these lesions. No evidence of diffusion restriction is noted in mentioned areas. Follow-up MRI: Complete recovery of the lesions are seen in the repeat MRI after chelation therapy

MRI findings of lead encephalopathy due to regular ingestion of opium have not been reported to date. In our study, three patients (33.3\%) showed abnormal MRI findings. Atre and colleagues reported encephalopathy due to Ayurvedic medicine with bilateral symmetric involvement of the parasagittal occipital, temporal, parietal and frontal lobes and a right cerebellar lesion. In the first patient of our study, the lesions dramatically resolved without chelation therapy. This may emphasize on the importance of cessation of lead exposure as the most effective treatment in lead encephalopathy [10].

Lead encephalopathy is usually associated with BLLs higher than $100 \mu \mathrm{g} / \mathrm{dL}$; but, there are few reports of encephalopathy with levels even lower than $70 \mu \mathrm{g} / \mathrm{dL}$ [11]. The minimum BLL in our study was $50 \mu \mathrm{g} / \mathrm{dL}$ and encephalopathy due to such low BLL might be due to the chronic nature of the toxicity. Lead encephalopathy can be seen even as low as $38 \mu \mathrm{g} / \mathrm{dL}$ in chronic cases suggesting demyelination process of lead toxicity [1]. This might be in accordance with previous study of Bouldin et al. indicating cumulative brain lead exposure and the best predictor of the prevalence of demyelination [12].

Bilateral symmetric involvement of the thalami and lentiform nuclei were reported in two patients with abnormal signal in external capsule and subcortical white matter in one patient [1]. Bilateral thalamic and T2-weighted high signal areas in the basal ganglia, posterior thalamus, pons, insula, and periventricular white matter have also been reported [11, 13]. In our patients, bilateral symmetric involvement of occipital, parietal and to a less extent, frontal and temporal lobes were observed. Gray matter, gray-white matter junction, and subcortical white matter were also affected.

Our patients' imaging results are similar to regular findings in posterior reversible encephalopathy syndrome (PRES) which is an acute neurotoxic state characterized by temporary neurological symptoms including acute headache, altered mental status, visual loss, and coma. PRES is mainly due to hypertension but other conditions including immunosuppression therapy, hypercalcemia, and chronic renal/hepatic failure can also lead to it. It is suggested that PRES is associated with endothelial damage and blood brain barrier (BBB) disruption [14].

Interestingly, organic lead is able to cross blood-brain barrier, accumulate in the brain tissue, and mimic or mobilize calcium ions. Lead can enter the brain not only by passive transport but also as the consequence of 


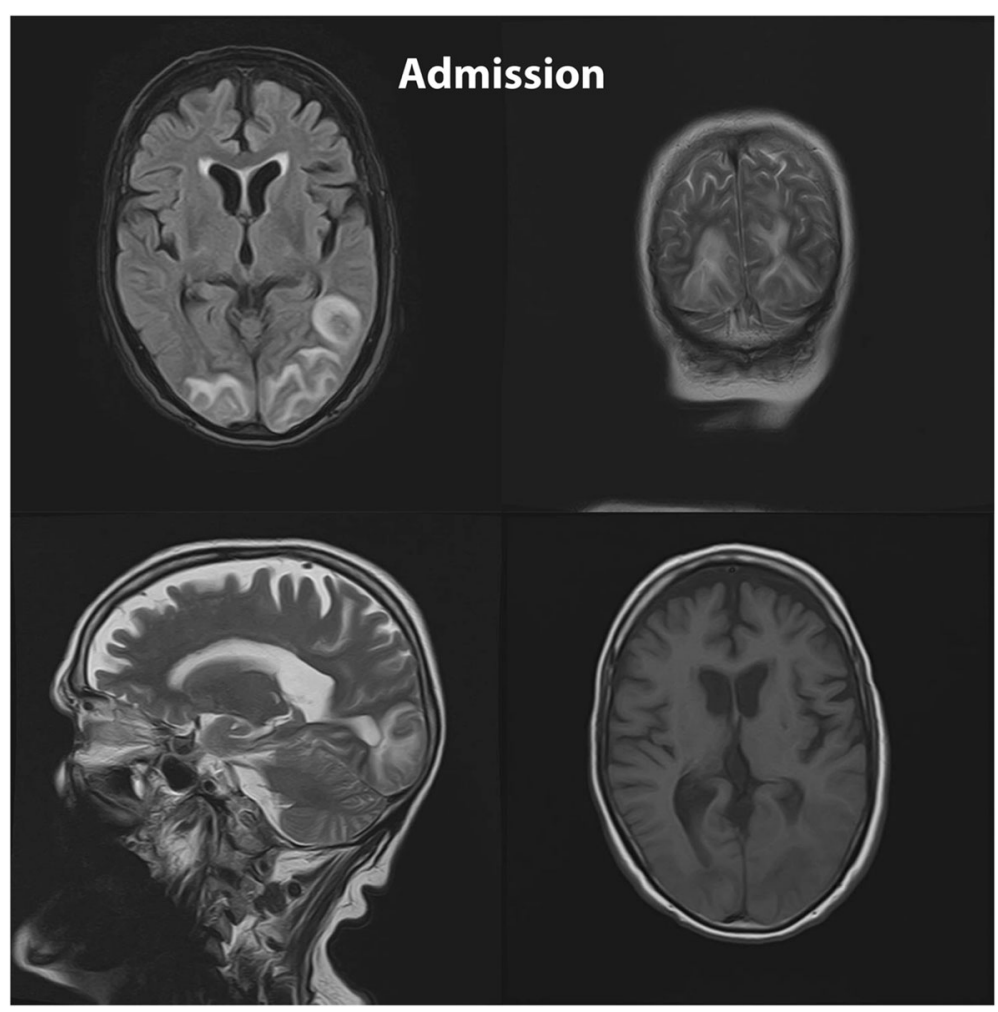

Fig. 3 (Case 2): Admission MRI: MRI shows symmetric involvement of the parasagittal areas of bilateral parietal and occipital lobes. Asymmetric involvement of bilateral posterior temporal lobes is also evident. The affected areas are gray matter, gray white matter junction, and subcortical white matter. The lesions signal on T2-weighted and FLAIR sequences are high and low on T1-weighted sequence. No evidence of Diffusion restriction is depicted in involved areas. This patient refused follow-up MRI after chelation therapy as he believed to be completely fine

changed BBB permeability. "Leaky microvessels" following endothelial dysfunction in lead excitotoxicity and PRES have the same MRI findings [15].

The data obtained in the study, although limited by the number of patients, is interesting because the patients' encephalopathy improved after discontinuation of the contaminated opium. Response to treatment ruled out other opioid-related complications such as "chasing the dragon" or hypoxic encephalopathy in our patients.

\section{Limitations}

We could only evaluate 9 out of 19 potentially eligible patients due to mortality and technical reasons. MRIs of the more severely poisoned patients would have been worse, but as these patients did not undergo MRIs, this cannot be known.

We have no access to the follow-up information of the patients that did not undergo the MRI, to know if all these patients presented reversible neurological symptoms.

\section{Conclusion}

One-thirds of our encephalopathy patients, that could be retrieved for follow-up MRI, had reversible abnormal MRI findings. With the knowledge on our limited cases, no correlation exists between the MRI findings and BLLs or clinical signs. BBB disruption could be the same mechanism for imaging findings in lead encephalopathy and PRES.

\section{Abbreviations}

BBB: Blood brain barrier; BLL: Blood lead level; CNS: Central Nervous System; EEG: Electroencephalography; Hb: Hemoglobin; IQR: Inter Quartile Range; MRI: Magnetic Resonance Imaging; PRES: Posterior Reversible

Encephalopathy Syndrome; SPSS: Statistical package for social sciences

\section{Acknowledgements}

None.

\section{Authors' contributions}

$\mathrm{HHM}$ is the guarantor of integrity of the entire study. MHM and MS gave the study concepts and designed the study. NZ, and MHM did the literature research. MHM and HHM performed the data and statistical analysis. NZ prepared the manuscript draft and HHM did edit the final manuscript. All authors have read and approved the manuscript.

\section{Funding}

This study was supported by Social Determinants of Health Research Center, Shahid Beheshti University of Medical sciences, Tehran, Iran (Grant no.

10307). The funding source had no role in study design, data collection, data analysis, data interpretation, writing of the article and the decision to submit the manuscript for publication. 


\section{Availability of data and materials}

The datasets used and/or analysed during the current study are available from the corresponding author on reasonable request.

\section{Ethics approval and consent to participate}

This study approved by Shahid Beheshti University of Medical Sciences ethics committee (IR.SBMU.RETECH.REC.1397.428). The informed consent from was waved due to retrospective nature of the study by ethics committee.

\section{Consent for publication}

Not applicable.

\section{Competing interests}

None.

\section{Author details}

'Department of Radiology, Loghman-Hakim Hospital, School of Medicine, Shahid Beheshti University of Medical Sciences, Tehran, Iran. ${ }^{2}$ Social Determinants of Health Research Center, Shahid Beheshti University of Medical Sciences, Tehran, Iran. ${ }^{3}$ Department of Clinical Toxicology, Loghman-Hakim Hospital, School of Medicine, Shahid Beheshti University of Medical Sciences, Tehran, Iran. ${ }^{4}$ Department of Neurology, Loghman-Hakim Hospital, School of Medicine, Shahid Beheshti University of Medical Sciences, Tehran, Iran

Received: 18 December 2019 Accepted: 26 April 2020

Published online: 01 May 2020

\section{References}

1. Rao JVB, Vengamma B, Naveen T, Naveen V. Lead encephalopathy in adults. J Neurosci Rural Pract. 2014:5:161-3.

2. Bramwell B. The differential diagnosis of Lead encephalopathy and intracranial Tumours. Edinb Med J. 1879;25:510-4.

3. Ghane T, Zamani N, Hassanian-Moghaddam H, Beyrami A, Noroozi A. Lead poisoning outbreak among opium users in the Islamic Republic of Iran, 2016-2017. Bull World Health Organ. 2018;96:165-72.

4. Zamani N, Hassanian-Moghaddam H. Lead contamination of opium - Iran, 2016. MMWR Morb Mortal Wkly Rep. 2018;66:1408-9.

5. Zamani N, Hassanian-Moghaddam H, Latifi M. Abdominopelvic CT in a patient with seizure, anemia, and hypocalcemia. Gastroenterology. 2017;152: 27-8.

6. Alinejad S, Aaseth J, Abdollahi M, Hassanian-Moghaddam H, Mehrpour O. Clinical aspects of opium adulterated with Lead in Iran: a review. Basic Clin Pharmacol Toxicol. 2018:122:56-64

7. Hassanian-Moghaddam H, Zamani N, Rahimi M, Shadnia S, Pajoumand A, Sarjami S. Acute adult and adolescent poisoning in Tehran, Iran; the epidemiologic trend between 2006 and 2011. Arch Iran Med. 2014;17:534-8.

8. Geibprasert S, Gallucci M, Krings T. Addictive illegal drugs : structura neuroimaging. AJNR. 2010;31:803-8

9. Borne J, Riascos R, Cuellar H, Vargas D, Rojas R. Neuroimaging in drug and substance abuse part II: opioids and solvents. Top Magn Reson Imaging. 2005;16:239-45

10. Atre AL, Shinde PR, Shinde SN, Wadia RS, Nanivadekar AA, Vaid SJ, Shinde RS. Pre and posttreatment MR imaging findings in lead encephalopathy. AJNR Am J Neuroradiol. 2006:27:902-3.

11. Mani J, Chaudhary N, Kanjalkar M, Shah PU. Cerebellar ataxia due to lead encephalopathy in adult. J Neurol Neurosurg Psychiatry. 1998:65:797-8.

12. Bouldin TW, Meighan ME, Gaynor JJ, Goines ND, Mushak P, Krigman MR. Differential vulnerability of mixed and cutaneous nerves in lead neuropathy. J Neuropathol Exp Neurol. 1985;44:384-96.

13. Schröter C, Schröter H, Huffmann G. Neurologic and psychiatric manifestations of lead poisoning in adults (case report and review of literature) [in German]. Fortschr Neurol Psychiatr. 1991;59:413-24.

14. Demirel İ, Kavak BS, Özer AB, Bayar MK, Erhan ÖL. An intensive care approach to posterior reversible encephalopathy syndrome (PRES): an analysis of 7 cases. J Turk Ger Gynecol Assoc. 2014;15:217-21.

15. Strużyńska L, Walski M, Gadamski R, Dabrowska-Bouta B, Rafałowska U. Leadinduced abnormalities in blood-brain barrier permeability in experimental chronic toxicity. Mol Chem Neuropathol. 1997;31:207-24.

\section{Publisher's Note}

Springer Nature remains neutral with regard to jurisdictional claims in published maps and institutional affiliations.

\section{Ready to submit your research? Choose BMC and benefit from}

- fast, convenient online submission

- thorough peer review by experienced researchers in your field

- rapid publication on acceptance

- support for research data, including large and complex data types

- gold Open Access which fosters wider collaboration and increased citations

- maximum visibility for your research: over $100 \mathrm{M}$ website views per year

At BMC, research is always in progress.

Learn more biomedcentral.com/submissions 